\title{
INCIDÊNCIA DE MENINGITE EM PACIENTES DE 0 - 12 ANOS NO INSTITUTO DE MEDICINA TROPICAL DE MANAUS
}

\author{
José F. S. Vieira ${ }^{1}$
}

\begin{abstract}
RESUMO - 0 autor analisa a incidência de meningite em pacientes com idade de 0 a 12 anos atendidos no Instituto de Medicina Tropical de Manaus durante um período de 2 anos. A doença foi correlacionada com agente etiológico, terapeutica empregada, evolução do paciente e cura, complicações imediatas, sequelas neurológicas tardias, bem como o óbito. Foi feito estudo comparativo dos resultados obtidos na prática hospitalar com a literatura, fazendo um perfil da situação da meningite no Estado do Amazonas.
\end{abstract}

PALAVRAS-CHAVE: meningite, incidência , Amazonas.

Incidence of meningitis in patients 0-12 years old in the Instituto de Medicina Tropical de Manaus

ABSTRACT - The author analyzes the incidence of meningitis in patients with age ranging 0-12 years old treated in Instituto de Medicina Tropical de Manaus, during a period of two years. The illness is correlated with the etiological agent, treatment, follow-up, immediate and late complications, as well as the death by the illness. Comparison of results in this hospital experience with the literature allows a profile of the situation of meningitis in the State of Amazonas, Brazil.

KEY WORDS: meningitis, incidence, Amazonas.

A meningite está relacionada com uma série de complicações tanto imediatas quanto tardias, que podem culminar com danos irreversíveis no sistema nervoso central (SNC), ou levar ao êxito letal. A doença ainda apresenta altos índices de morbidade e mortalidade. A meningite ainda é um problema bastante complexo na patologia humana e também para a saúde pública. Isto é muito importante pela elevada frequência com que se faz o diagnóstico da doença na prática médica e, em particular, na prática pediátrica. A letalidade da doença meningocócica é alta na maioria dos países da América Latina. O Estado do Amazonas registra ainda uma taxa mais elevada, em face da precariedade sócio- econômica da nossa população ${ }^{1.2}$.

No Amazonas, existem poucos estudos sobre esta doença. Os únicos dados estatísticos encontrados, foram levantados no ano de 1988, quando foram registrados 121 casos com 25 óbitos no Estado, sendo 82 casos com 18 óbitos na capital e 39 casos com 7 óbitos no interior ${ }^{2}$.

A literatura médica refere que as crianças, além de serem as mais atingidas pela meningite, são as que mais complicam e evoluem para óbito especialmente quando em faixas etárias mais tenras, devido a imaturidade do SNC.

Baseado na escassez de levantamentos estatísticos, a alta incidência e letalidade da patologia, principalmente em crianças (que são as que mais apresentam complicações), e sendo o único centro hospitalar especializado no Estado para receber pacientes com esta patologia o Instituto de Medicina Tropical de Manaus (IMTM), surgiu então a iniciativa deste levantamento.

\section{MÉTODO}

Foram analisados os dados prospectivos de pacientes internados e acompanhados com meningite infecciosa no IMTM, no período de agosto de 1993 a julho de 1995, verificando-se os seguintes dados: agente etiológico, terapêutica utilizada, evolução do paciente e cura, complicações tanto imediatas como tardias, sequelas neurológicas e óbitos pela doença. Com os resultados obtidos foi feito estudo comparativo da prática hospitalar do IMTM

Disciplina de Neurologia / Neurocirurgia, Departamento de Clínica Cirúrgica, Faculdade de Ciências da Saúde, Universidade Federal do Amazonas e Instituto de Medicina Tropical de Manaus, Manaus AM, Brasil: ${ }^{1}$ Professor Adjunto IV do Curso de Medicina. 
com a literatura e um perfil da situação da meningite no Amazonas.

Os pacientes cadastrados tinham entre 0 - 12 anos completos; crianças com 12 anos e 1 dia e com 12 anos e 1 mês, e assim sucessivamente, não entraram no estudo. Participaram os pacientes internados e que fizeram controle ambulatorial no IMTM, tendo que ter necessariamente o diagnóstico definitivo de meningite infecciosa.

A metodologia foi subdividida em duas fases, da seguinte forma:

Fase I - constou da evolução clínica, efetuada diariamente. Uma vez diagnosticada a doença, o paciente era acompanhado com a realização do exame físico para detecção das principais alterações e complicações gerais da meningite; sendo realizado o exame do líquido cefaloraquidiano (LCR) para detecção do possível agente etiológico da meningite. O exame físico foi realizado com a criança no leito hospitalar, sendo os sintomas sugestivos da doença computados para posterior avaliação. Passado o estado crítico da doença, o paciente era transferido para Enfermaria Pediátrica do Hospital, onde continuava sendo acompanhado. Os pacientes que evoluíram para óbito foram submetidos a exame necroscópico, sendo o laudo também computado para posterior avaliação.

Fase II - foi realizado o exame neurológico diariamente nos pacientes internados na área de isolamento e enfermaria pediátrica do IMTM para detecção das complicações e alterações neurológicas imediatas.

O exame do LCR foi realizado na internação do paciente, e a cada sete dias foi realizado novo exame para controle de evolução.

Os pacientes uma vez passados pelas Fases I e II, após alta hospitalar, foram instruídos a fazer controle ambulatorial no IMTM em um intervalo de um mês.

No ambulatório, foram realizados os exames geral e neurológico para observação do desenvolvimento neuropsicomotor, o que possibilitou não só o diagnóstico de sequelas e complicações neurológicas tardias, como também sua interação social (escola, relacionamento com os pais e outras crianças). Em caso de detectar qualquer alteração nesse sentido, o paciente era encaminhado ao Serviço Social do Hospital.

O controle epidemiológico foi realizado através de entrevista com questionário padronizado, investigandose a procedência, casos familiares semelhantes e em áreas vizinhas, nível sócio- econômico, ambiental e nutricional. Resgatando- se o contato com o paciente, através de cartas, telefonemas e visitas residenciais, quando possível, com o fim de melhorar a verificação de dados e o controle da computação, para evitar maior fuga de informações.

\section{RESULTADOS}

Foram acompanhados nos dois anos de execução da pesquisa, 202 pacientes, sendo 105 (51,98\%) do sexo masculino e 97 (48,02\%) do feminino. 0 acompanhamento se deu através da evolução dos exames complementares realizados.

Observamos que a etiologia variou de acordo com a faixa etária, porém maior responsável pela morbidade em todas as faixas foi a meningite bacteriana indeterminada.

Em termos gerais a meningite bacteriana indeterminada foi a que mais incidiu perfazendo um total de 70 casos (34,7\%). Seguida, em ordem decrescente de frequência, pela meningite viral 43 casos $(21,29 \%)$, por Hemophilus influenzae 35 casos $(17,32 \%)$, meningocócica 34 casos (16,8\%), pneumocócica 12 casos $(5,9 \%)$, tuberculosa 6 casos $(2,9 \%)$ e meningite estafilocócica 2 casos (0,9\%).

Dos 202 casos de meningite registrados no IMTM, no período de agosto 93 a julho 95, 171 (85\%) evoluíram para cura e 31 (15\%) foram a êxito letal. A menor faixa etária (0-2anos) foi a que mais evoluiu para óbito, num total de 22 (70,97\%). A meningite bacteriana indeterminada foi a etiologia de maior letalidade perfazendo 16 mortes $(51,61 \%)$.

Da nossa amostragem, 119 pacientes $(58,9 \%)$ evoluíram sem intercorrências, 83 (41,1\%) cursaram com alguma complicação. Foram detectados 34 tipos de complicações sendo as mais frequentes: crise convulsiva, 38 casos (45,8\%), coma 21 (25,3\%), hipertensão intracraniana $18(21,7 \%)$, meningoencefalite 17 (20,3\%), lesões petequiais 12 (14,45\%), parada cárdio- respiratória-central $11(13,25)$, abscesso cerebral 10 (12,05\%).

Dentre as complicações neurológicas imediatas incluem-se: hidrocefalia 4 casos (4, 8\%), ptose palpebral unilateral 4 (4,8\%), paralisia de pelo menos um músculo extrínseco do globo ocular, incoordenação motora, 3 casos de cada (3,6\%), nistagmo 2 casos $(2,41 \%)$. Foram ainda encontrados 8 tipos de sequelas neurológicas, como segue: desenvolvimento neuropsicomotor prejudicado 8 casos $(44,4 \%)$, déficit intelectual 5 casos $(27,8 \%)$, hemiplegia 3 $(16,6 \%)$, incoordenação motora e disfasia 2 casos cada $(11,1 \%)$, hidrocefalia, ptose palpebral unilateral e estrabismo 1 caso cada (5,5\%).

Realizamos ainda um levantamento relacionando o agente causador versus complicação, sendo o bacilo de Koch o responsável pelo maior percentual, pois dos 6 casos incidentes $(2,9 \%)$, apenas 1 paciente $(16,6 \%)$ evoluiu sem complicação.

\section{DISCUSSÃO}

Nestes dois anos de execução da pesquisa observou-se a inconstância da incidência de meningite. 
Isso porque, no primeiro ano os casos da doença mantinham-se relativamente estáveis numa média de seis casos mensais. Porém, no segundo ano a incidência adquiriu um caráter sazonal, com pico mensal de até 26 casos.

Não foram encontradas grandes divergências entre a prática médica avaliada no Instituto de Medicina Tropical de Manaus e o que rege a literatura ${ }^{3-12}$, consolidando-se dessa forma a observação de que, apesar de nossa região apresentar características tropicais, com o clima muito quente e úmido, não houve interferência em relação a uma maior manifestação da doença. Observamos ainda que as condições sócio-econômicas peculiares desta região, também não alteraram significativamente a prevalência da doença. Não se observou diferença significativa entre sexos. A maioria dos casos é de etiologia bacteriana, entretanto, é difícil compararmos a bactéria de maior frequência, pois em $37,7 \%$ das meningites não se determinou a etiologia.

É importante ressaltar que o prognóstico associado às meningites é influenciado pela precocidade do diagnóstico e pela introdução da terapêutica adequada; principalmente em relação a criança, visto que, as crianças são as mais acometidas, e que mais evoluem para óbito.
Agradecimentos - Aos Acadêmicos de Medicina Nancilene Gomes Melo e Silva, Richard Lester Khan e Nely Wanda da Silva Alencar pela contribuição que deram no levantamento e compilação de dados.

\section{REFERÊNCIAS}

1. Farias RH, França MLF. Perfil epidemiológico das doenças trasmissíveis no Estado do Amazonas. Manaus: Governo do Estado do Amazonas Secretaria de Estado da Saúde - Coordenadoria de Epidemiologia Setor de Análise, 1989: 20,21.

2. Vale SA, Jezine AM. Rocha AJ. Perfil epidemiológico do triênio no Amazonas. Manaus: Governo do Estado do Amazonas - SESAU Coordenadoria de Epidemiologia - Setor de Análise, 1988-1990 $45,88,89,90$.

3. Ramos SRTS, Feferbaun R, Manissadijian A, Vaz FAC. Meningite bacteriana neonatal:agentes etiológicos em 109 casos durante período de dez anos. Arq Neuropsiquiatr 1992;50:289-294.

4. Tonneli E. Doenças infecciosas na infância. São Paulo: Ed Meds 1987:365-372,997-1000.

5. Veronesi R. D.M.D.L. 7.Ed. Rio de Janeiro: Guanabara-Koogan, 1982:490-504.

6. Krugman S, Warel R, Kartz SL. Doenças infecciosas em pediatria. 8.Ed. Rio de Janeiro: Ateneu, 1991:207-224.

7. Sylver HK, Kempe H, BruynHB. Manual de pediatria. 14.Ed 1985:544-584.

8. Silva RJM, Barbato JH Filho, Marchesini C, Budag R . Meningites bacterianas e agudas na criança: assistência médica e de enfermagem. Arq Catarin Méd 1990;19: 139-142.

9. Gomes MCO.Como diagnosticar e tratar meningite. Rev Bras Med 1988;15.9.

10. Baldy JLS, Amato Neto . Doenças transmissíveis. 3.Ed. São Paulo: Sarvier, 1989:266,268,603,615.

11. Wyngaarden JB, Smith Jr L. Cecil-tratado de medicina interna.16.Ed. Rio de Janeiro: Interamericana, 1984:1500-1554.

12. Prado FC, Ramos J, Valle,JR. Atualização terapêutica. Manual prático de diagnóstico e tratamento. 13.Ed. Porto Alegre: Artes Médicas, 1991:9-11. 